\title{
Business Model Innovation Leadership: How Do SME’s Strategically Lead Business Model Innovation?
}

\author{
Peter Lindgren ${ }^{1}$ \\ ${ }^{1}$ Department of Mechanical and Manufacturing Engineering, Aalborg University, Aalborg, Denmark \\ Correspondence: Peter Lindgren, Department of Mechanical and Manufacturing Engineering, Aalborg University, \\ Aalborg, Denmark. Tel: 45-29-79-49-69. E-mail: pel@m-tech.aau.dk
}

Received: January 28, 2012

Accepted: June 6, 2012 Online Published: July 16, 2012

doi:10.5539/ijbm.v7n14p53

URL: http://dx.doi.org/10.5539/ijbm.v7n14p53

\begin{abstract}
When SME's practice business model (BM) innovation (BMI), leading strategically BMs through the innovation process can be the difference between success and failure to a BM. Business Model Innovation Leadership (BMIL) is however extremely complex to carry out especially to small and medium size enterprises (SME). There are so many opportunities, pitfalls and strategies to consider while "the business" has to be operated simultaneously.

The paper provides a study of BMIL in practise in SME's and show different ways of how they handle BMIL and BMIL strategies. The SME's were examined through a framework model called the BMIL strategy canvas. The research approach was action research carried out from 2008 - 2012. Intense study of 35 US and EU SME's and 97 of their different BM's form the empirical background. The findings represent learning and characteristic of BMIL with a strong reference to state of the art theory in BM and BMI.

The research reveals that SME's focus on very classic BMI approaches and BMIL strategies. SME's focus in most cases on reactive "outside in and reactive "inside in" BMIL strategies. SME's are primarily focusing on meeting needs and demands of an inside out "predefined" set of user and/or customer groups. SME's are reacting to a specific customer or market demand but the BMIL strategies do often not put them in a better or more central strategic position in their market and industry - and in the BMI process.

The research shows some common approaches about SME's BMI and BMIL strategy - Specifically, 1) Most SME's do not formulate explicitly a BMIL strategy - they are doing BMI rather blindly 2) Very few SME's are structured about their BMIL strategy and BMIL strategy process 3) SME's focus in their BMIL on very few and often the same building blocks of the BM - especially the building blocks value proposition, target customer and value chain [Internal] - often regardless of the actual specific BMIL task, market demand and context of BMI 4) SME's often leaves big BM potential behind because they cannot see the potential and are often not able to capitalised upon these 5) SME's is generally in lack of BMIL skills.
\end{abstract}

Keywords: business model innovation leadership, business model, business model innovation strategy

\section{Introduction}

Business model (BM) and Business Model Innovation (BMI) has been the focus of substantial attention by both academics and practitioners (Zott 2011), (Teece 2012). The BM has been the subject of a still growing number of academic and practitioner-oriented studies. While there has been an increasing number of papers published, fast growing communities on BM's (Business model Communities 2012) and an abundance of conference sessions and panels on the subject of BM's, it appears that researchers and practitioners have yet not researched widely on, what are SME's BMI strategies and what are SME's strategically doing when they practice BMI. Especially the strategic leadership part of BMI has not yet thoroughly been studied and there is not much knowledge about how BMI strategically is carried out in SME's.

There is until now no accepted language for BM (Zott 2010) and neither for strategic BMI that would allow researchers who examine strategic BMI through different lenses to draw effectively on each other's' work. The study takes up the challenges by reporting and giving some first insight to the strategic part of BMI. The paper intend to answer the research questions

How do SME's strategically practice BMI? 
How do SME's practice BMI leadership (BMIL)?

Which types of BMIL can be identified in SME's?

The paper begins with a broad and multifaceted review, which revealed several insights and enables the development of a generic framework on BM, BMI and strategic BMI. In this context the paper builds upon a comprehensive review of academic literature including the origin of the BM concepts, BMI and Strategic Innovation Leadership. The paper ends up reporting the results of the research and proposing a terminology on strategic BMIL framework.

\section{The Literature and Definition of Business Model Innovation Leadership}

Academia's have studied both implicit and explicit assumptions about BM (Magretta 2002, Afuah 2003, Morris 2003, Osterwalder 2004, Chesbrough 2006, Johnson 2008, Lindgren 2010, Taran 2011, Zott 2010, Teece 2011, Lindgren 2012). In this context our research builds upon the following terminologies

The Business Inspired by (Abell 1980), (Porter 1985), (Hammel 1985), (Vervest 1995), (Johnson and Christensen 2010) where we define a business defined on 7 dimensions:

1) Value proposition - Value proposition (product, services and process of service and products) rendered by the business

2) Customer Groups - user and customer groups served by the business

3) Value Chain [Internal Part] - Value Chain functions carried out, used to produce value proposition (products and service) and serve users/ customer groups in the business

4) Competences - used technology (product, production, process technologies), human resource, organizational system, culture used in the business

5) Networks - Networks - physical, digital and virtual used in the business

6) Relations - tangible and intangible relations used in the business

7) Value formular - value formular for the business

Most Academia covers the term Business Model at an overall business level. This could be related to the term The core Business (Abell 1983, Hammel 1995) which is

"How a business idealized construction and intend for "main" and "essential" business activities we propose defined related to the 7 business dimensions"

However in our research we found that most business have a variety of activities in the business - a variety of business models. These different BM's can often not be explained strictly by one core business model - a model of the business. As a consequence a business can be said to have one or more business models - the multi business model approach (Lindgren 2011). However any of these BM's can be define as related to a generic Business Model consisting of 7 generic building blocks that answers some core questions to each BM

Table 1. 7 Building blocks of a BM (Lindgren 2011)

Core questions related to $\mathrm{BM}$

$\begin{array}{ll}\text { Core building block } & \text { Building blocks }\end{array}$

Value proposition/s (products, services and processes) that the What value proposition do we provide? company offers (Physical, Digital, Virtual)

Target users and customer/s, (users customers, market segments that the company serves - geographies, physical, digital, virtual).

Value chain [internal] configuration.(physical, digital, virtual)

Who do we serve?

Competences (assets, processes and activities) that translate

What value chain functions do we provide? How do we provide it?

company's' inputs into value for customers (outputs).(Physical,

What competences do we provide? digital, Virtual)

Network- Network and Network partners (e.g. strategic What is our network? partnerships, supply chains and others (Physical, digital, virtual) 
Relations(s) Relationship(s) (e.g. physical, digital and virtual What are our relations?

relations, personal, peers). (Physical, digital, virtual)

Value formula Profit formula - Both turnover structure, cost

What is our value formula?

structure and revenue flow and other value formula. (physical,

digital, virtual)

The BM is considered in most literature as measurable, objective, and though there are many different definitions (Taran 2011) and types of Business models (e.g., open and closed business models (Chesbrough 2008, Lindgren 2011), free business models (Anderson 2009), internet based business models (Zott 2002), multi business models (Lindgren 2010) most define business model on a business level and at a core business level. The paper propose that there is a need for a distinction between Business, core Business and BM's to prevent fuzziness and even make the BM framework useful to a business and especially related to a BMI context.

When a business is considered to have more than one BM in its Business and the BM's together forms one or more portfolio(s) of BM's in the business (Lindgren 2011) this enables the business to do BMI on both a building block level, a BM level, a BM portfolio level and a Business level. BMI can in this context both be valuable and focused on BM on the way to the market (TO BE) BM and in the market (AS IS) BM illustrated in the model beneath.

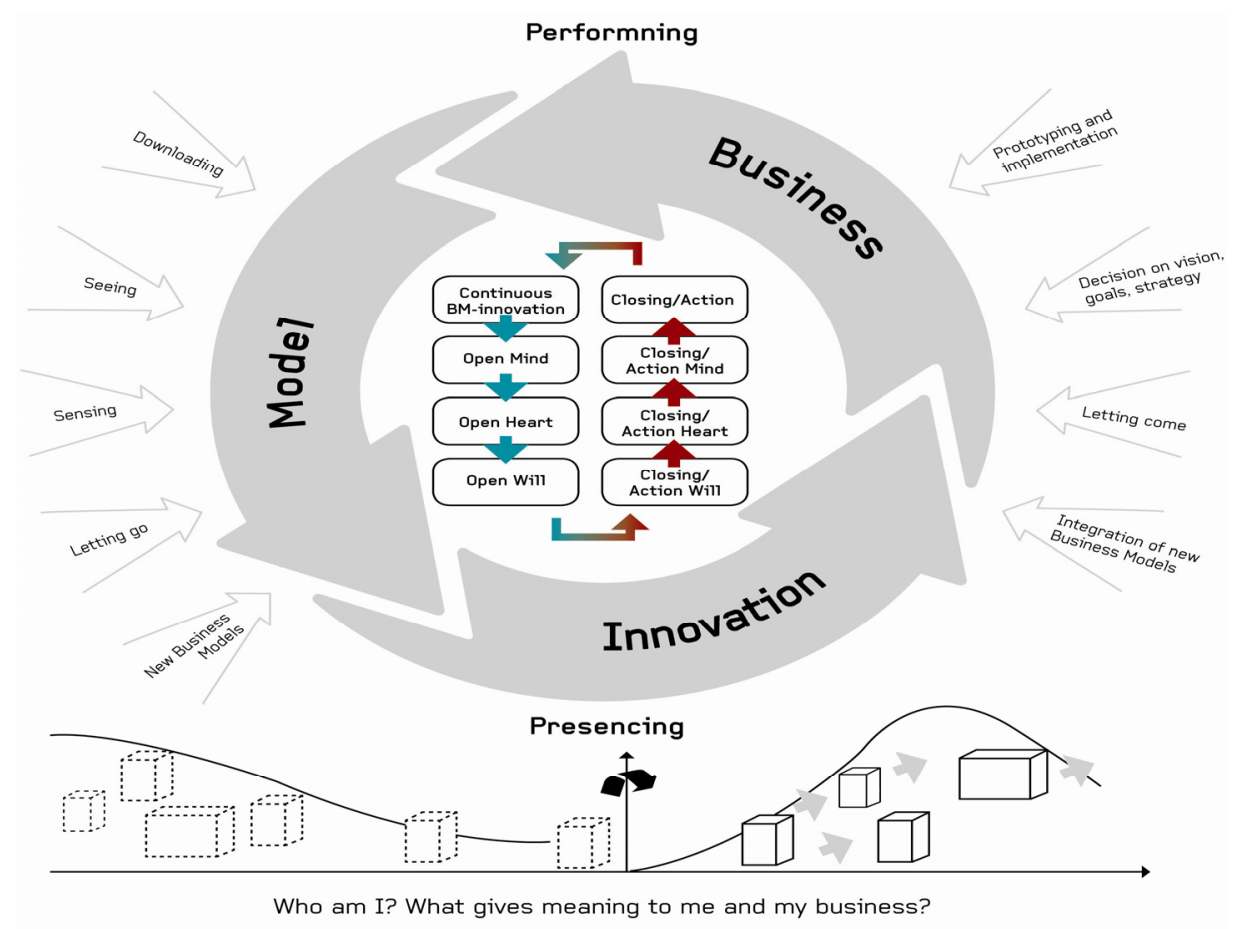

Figure 1. "AS IS" and "TO BE" BM in a business

Source: Lindgren and Saghaug 2011

This calls of course for BMI strategic overview, analysis, strategies and actions in each individual business, which could be related to Business Model Innovation Leadership (BMIL).

\subsection{Introducing Business Model Innovation Leadership (BMIL)}

Academia's have thoroughly studied innovation (Schumpeter 1957, Boer 2001, Ulrich and Eppinger 2000, Tidd 2005, Chesbrough 2005). In this context BMI was proposed defined as the tree of innovation (Taran 2011) to a Business, as the BM covers all the building blocks a business can innovate on.

Innovation leadership and management has also been discussed among academics for many years (Brymann 2004), (Rooke 2005) but not particular in a BMI context. The literature study on leadership shows that leadership studies have mainly been focused at the manager and at manager role when leading the business. In this paper the focus is on the strategic part of BMIL in particular 
- $\quad$ the strategic creative part of BMI - BMI thinking and BMI mindset related to innovating each building blocks of each BM ( both TO BE and AS IS (Lindgren 2011)) in the business.

The strategic implementation and action part - strategic BMI implementation with the aim of achieving and reaching strategic BMI goals for the business.

The focus on how strategically and proactively to lead the business and its related BM's (both "AS IS" and "TO BE" BM's) into the core of the BMI process with the aim of gaining access, staying in and gaining value and influence of the BMI process is regarded as the aim of BMIL. The BMIL's strategic goal could hereby be defined as to

- bringing the business into "the core of the BMI process"

- bringing the business into a better strategic BMI position in the core of the BMI process"

The core of a BMI process can be defined as

- Where BMI is actually taking place and where the business(es) has(ve) the opportunity to join, influence and even strategically lead BMI and the BMI process.

The opposite - being left outside the core of BMI process - often leaves businesses with no or reduced opportunities and no or reduced influence to join and change the BMI process. This position is of course not a strategic preferable position for a Business.

Managers today pay more and more attention to the factum that most BM's are constantly in change - and with more and more speed (Fine 2005, Lindgren 2011) - BMI are under continuously innovation pressure. The demand for BMI is therefore increasing, forcing a greater percentage of SMEs to make BMI faster in the face of frequently changing BM context and high-velocity BM environments. This often leaves the Business with the challenge - How to strategically stay in the core of the BMI process?

These challenge and question was the main motivation for our research interest and focus about strategic BMI. How do SME 'S really do BMI? And what types of strategic BMI do they really practice? Although the issue of How to do BMI is not new to BMI studies very few have addressed the question of How to be strategic about BMI. In this context some research show that costs, performance and time have been important focus point for BMI - but not as such in a strategic perspective. In the BMIL framework other success criteria seems also to be important values, learning, short and long term perspectives, strategic importance of a specific BMI project with the aim to bring and keep the business in the core of BMI process.

Many businesses have learned to do BMI and if not, they could be taught to do BMI. However still many business struggles to survive and get return on investment of their BMI projects. It seems as if very few businesses are able to do BMI strategically with advantage to the business. BMIL - observed in our research-seems indeed to be very complex to practice - especially to SME's, because there are so many opportunities, pitfalls and strategies to follow - together with the fact that there are very few service tools to support them (Neffics 2010).

Learning from strategic BMI practice is therefore considered as some first "raw material", inspiratory and driver to any SME's BMI. BMIL - changing BM's, finding new BM's and leading them to and in the market turns out indeed to be quite a different strategic matter related to previous proposed leadership and innovation leadership strategies and practice. Why - because BMIL is opposite to previous strategy proposals related to continuously finding new ways of changing and realizing both "AS IS" and "TO BE" BM's.

This does not in particular have to be narrowly focused on just product and market innovation - but could also innovation of other building blocks of any BM in the business BM portfolio. BMIL should preferable therefore be placed at the very strategic level of managing a business as it address where "AS IS" BM are changed and where "TO BE" BM are created, captured, delivered and consumed. It is where BMI is taking place, carried out before, under and beyond - idea, concept, prototyping, market implementation. (Lindgren 2012)

BMIL should aim at increasing the SME's BMI capability and capacity by optimizing the business BMI investment via creating, excluding, keeping, upgrading and diminishing value proposition offered, users and customers served, function in the value chain [internal] served, competence used, network used, relations and value formula used. The aim is to strategically improve existing BM's position and strategically finding new positions for the BM's in the business model context.

In BMIL context we differentiate between Business Model Innovation leadership (BMIL) and Business Model Innovation management (BMIMA) - as we consider the Leadership part as related to the strategic part of BMI and management related to the tactical level of BMI. BMIL focus on "How to strategically and proactively lead 
the business portfolio of BM and BM innovation activities into the core of the BM innovation process?"

Business model Innovation Management (BMIMA) focuses on "How to tactically and proactively lead the business portfolio of BM and BMI activities through the BM innovation process."

BMIMA is in our context related to the definition of management (Cooper 1993, Bessant 1999, Riis and Mikkelsen 2005) whereas BMIL is related to Hammels (Hammel 1995), Porters (Porter 1985) and Kotlers (2008) thoughts about strategic leadership. However BMIL goes beyond their definition, which we will later comment on.

\subsection{Business Model Innovation Leadership (BMIL) and Different Strategy Frameworks}

When BMIL is related to both a strategic creative part - continuously thinking out of the box and stressing the BMI mindset by questioning every building block of every BM from different angles or view points and also related to an implementation and action part - reaching change and business advantage for the business via implementation of a BMIL strategy it is obvious to analyze, which BMIL strategies are available. Several academia's have previous developed different strategy frameworks for business, competition, innovation, which give us a basis and inspiration for formulating BMIL strategy framework. However in the context of BMIL it seems as if there is a need for different strategies. Different strategies to different BM's - as the context of BMI today seems very different to every BM. A single strategy seems not to be appropriated.

However our inspiration and point of entry to propose such BMIL strategies and framework must build upon a careful respect and analysis of previous strategy frameworks strength, weaknesses, opportunities and threats. The new context of today's BMI does not automatically neglects previous achieved strategy knowledge.

\section{Introduction to BMIL Strategies}

Before introducing BMIL strategies we need to comment on some general issues and fundamental conditions when formulating a BMIL strategy. We do this by exemplifying the BMIL strategy issues via our use cases.

\subsection{Research Methology}

The research approach is action research carried out over 4 years. Intense study of US and EU SME's and their different BM's form the empirical background. Our research is carried out on 35 SME enterprises and 97 of their BMs. The research can only give some indicative measures of what some SMEs are doing related to their BMs, BMI and BMIL strategy.

\subsubsection{Different BM calls for Different BM Innovation Leadership Strategies}

The different BMs in our use case research show clearly that each BM calls and could value from different BMIL strategies. The BMI task, context and success criteria were simply very different in each BMI case. This is shown with different use cases verifying different BMIL context and strategies.

The Cancer BM in the Katalabs case shows an example of this statement, as this BM called for BMI on a network basis and Katalabs Open space system BM called for more customer innovation. Each BMI task could be related to BMI on one or more - often more - building blocks in the BM as shown in the table beneath.

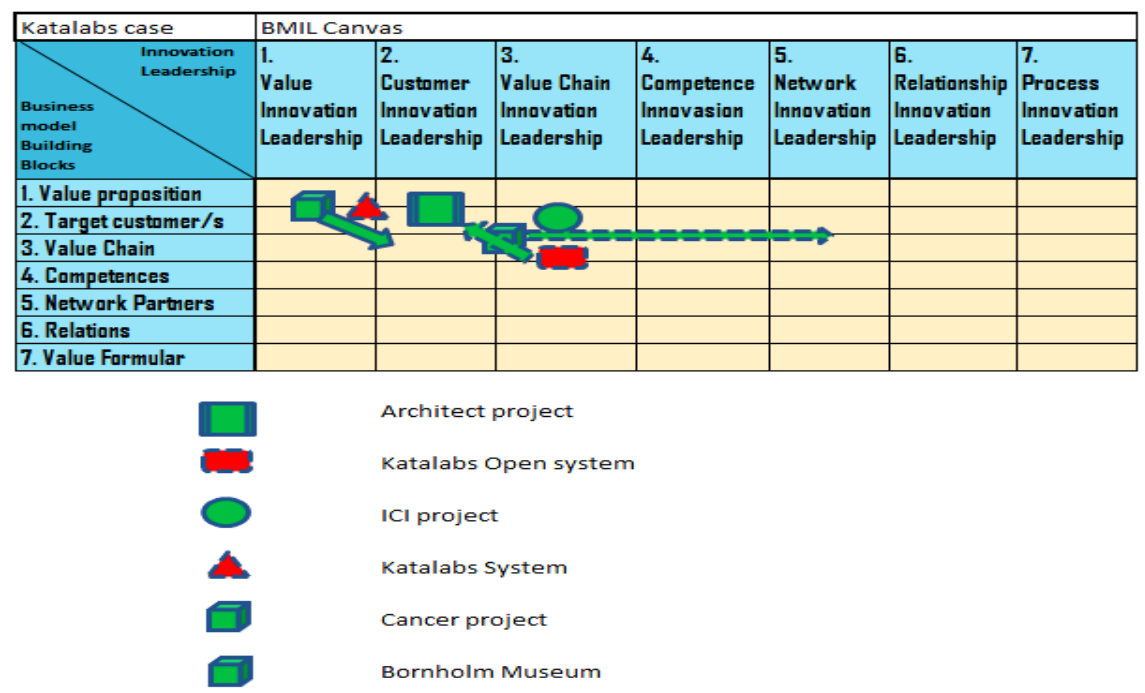

Figure 2. Katalabs case - BMs related to different BMIL tasks 
In the Katalabs case the BMIL canvas was characterized differently for different cases - with the BMIL tasks primarily at the upper left corner of the BMIL canvas - very much focused on value innovation-, customer innovation- and value chain BMI - "As IS" BMIL strategy.

Just by making this overview - Business Model Innovation strategy map - managers responsible for BMI and BMIL strategy could see and sense what they were really doing related to BMI and what their BMIL strategy really was about. The "mapping" of their BMI activities and BMIL strategies - or lack of BMIL strategy could support their strategy thinking and do better analysis of BMI and BMIL strategies.

This finding motivated us to study more in detail what other use case businesses were really doing related to BMI and BMIL strategy.

\subsubsection{SMEs BMI Strategy Related to the BMIL Matrix}

The cross business and BMI analysis adds some interesting characteristics to our understanding of SME's BMI and BMIL strategy practice and formulation. We found that $51 \%$ of the BMI projects were focused on two BM building blocks - Value Proposition and Target customer. Adding a third building block - Value Chain - to this shows us that SMEs BMIL strategy totally can be explain within these 3 building blocks with $68 \%$.

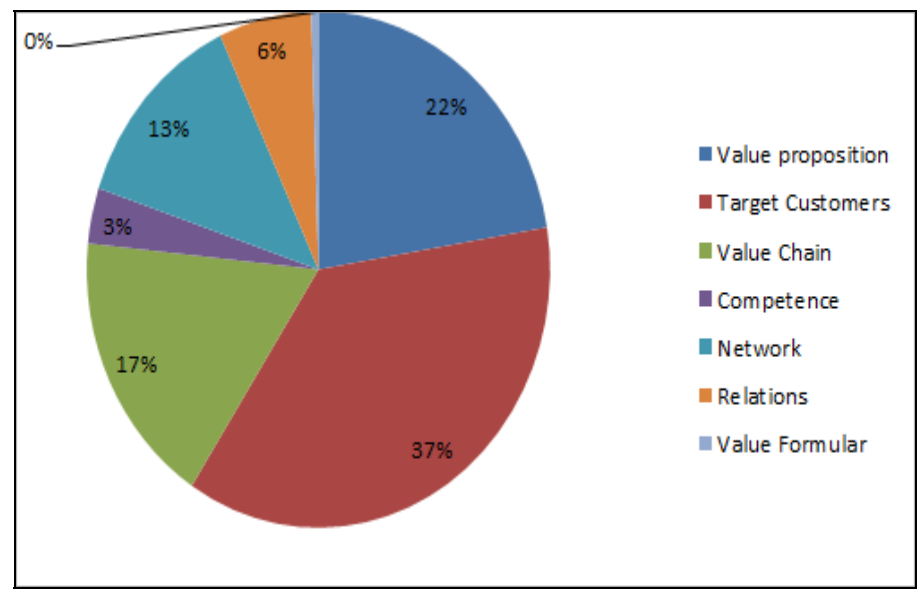

Figure 3. SMES general BMI focus related to building blocks in the BM

Focusing on BMI related to "AS IS" BMs, the numbers show $54 \%$ and $74 \%$ and for "TO BE" $49 \%$ and $62 \%$. The picture looks a bit different for "TO BE" BM because the network partner and the Relations building block seem to be more important in Businesses BMI.

Looking at which innovation leadership lines SME's chose related to BMI shows that SMEs mainly focus on Customer Innovation Leadership (CIL), Network Innovation Leadership (NIL) and Value Innovation Leadership (VIL). Please see the definition of VIL, CIL and NIL in appendix 1.

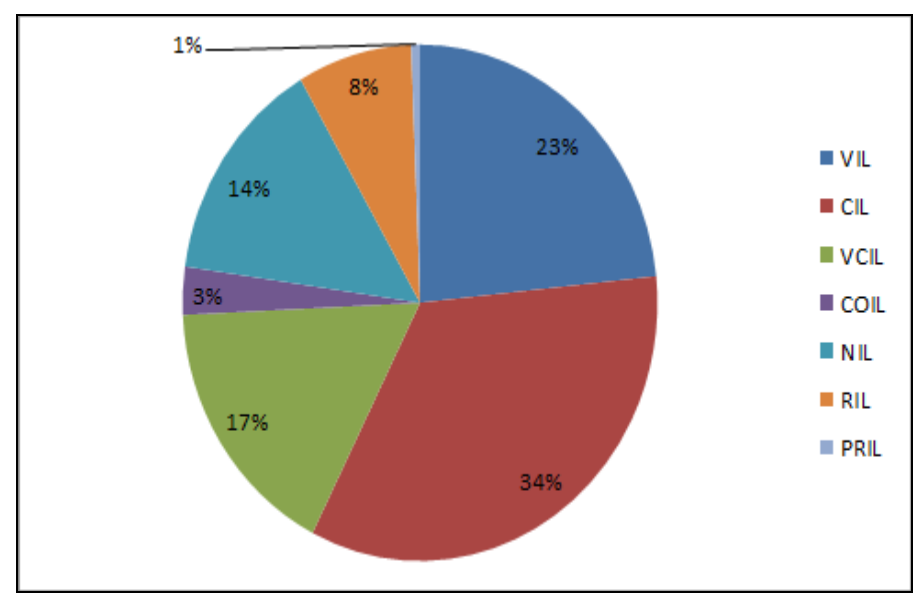

Figure 4. SME's choice of innovation leadership line related to BMI 
This support the argument that SME's are very traditional and to some level very conservative in their approach to BMI and choice of BMIL strategy (Hammel 1995). However we saw a clear trend - especially in 2009-2012 towards a more network based approach and focus on network partner building block in the BM and NIL. SME's begin to be more aware of the importance of networks and the network building block - involving more and more network partner and networks into the BMI process.

As BMI becomes more network based (Taran 2010) the focus on Network Partners value proposition and their demand for value becomes more in focus. The innovation leadership line NIL becomes more important. However more SMEs realized that in this BMI process the network partners demand for value and output of BMI is not necessarily related to products, services and profit. They can be very different than for traditional customers demand for values - products, services and processes of product and services. They could aim at getting learning, wish to experiment, sustainability and fulfillment of values to their own customers and/or network partners further out in different and other BMI processes.

"AS IS" BM compared to "TO BE" BM seems to have a different Innovation Leadership approach. We registered a small shift in focus related to "AS IS" and "TO BE" BM during the time periode of our research.

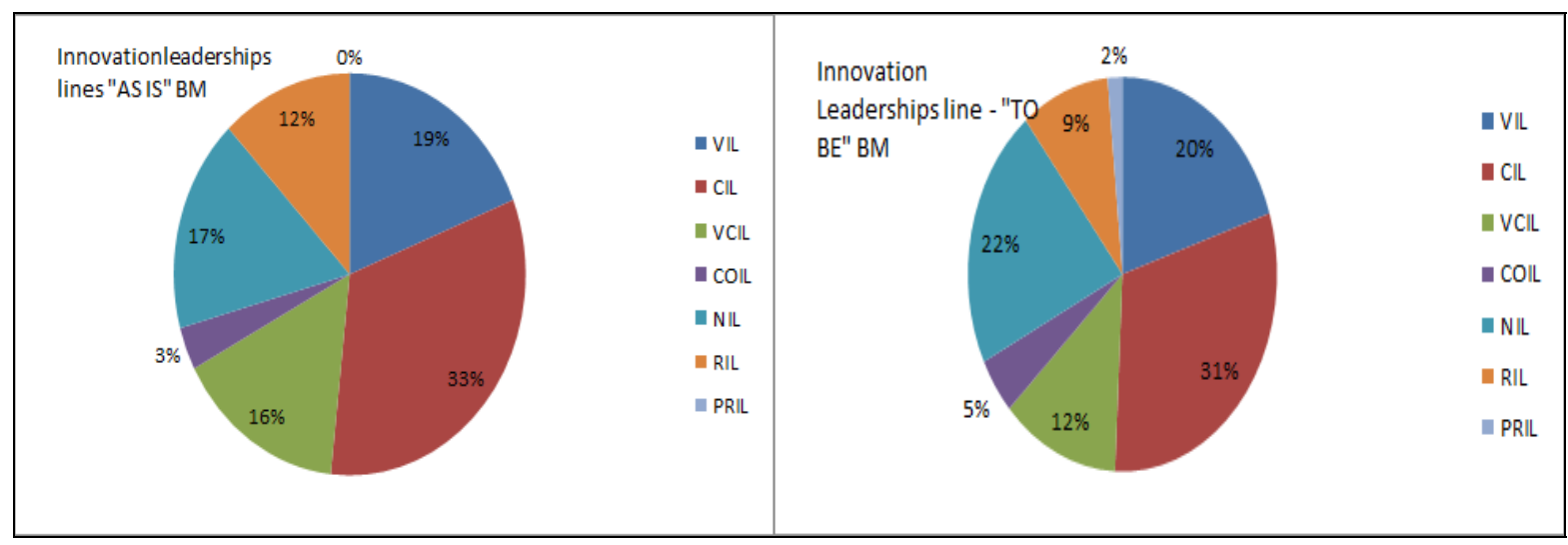

Figure 5. SME's choice of innovation leadership line related to BMI focus on "As IS" and "TO BE" BM's

The choice of Innovation leadership lines is not much different on "AS IS" as "TO BE" BM. However it seems as if NIL is a bit more in focus on "To Be" BM.

Going through the 24 use cases in our research we found that each BM had very different BMI tasks and context. BM's called in general for different BMIL strategies. In the Kellpo case - a Danish machine and machine tool producer - we found that the BMI tasks were spread over the BMIL canvas as illustrated in the figure beneath.

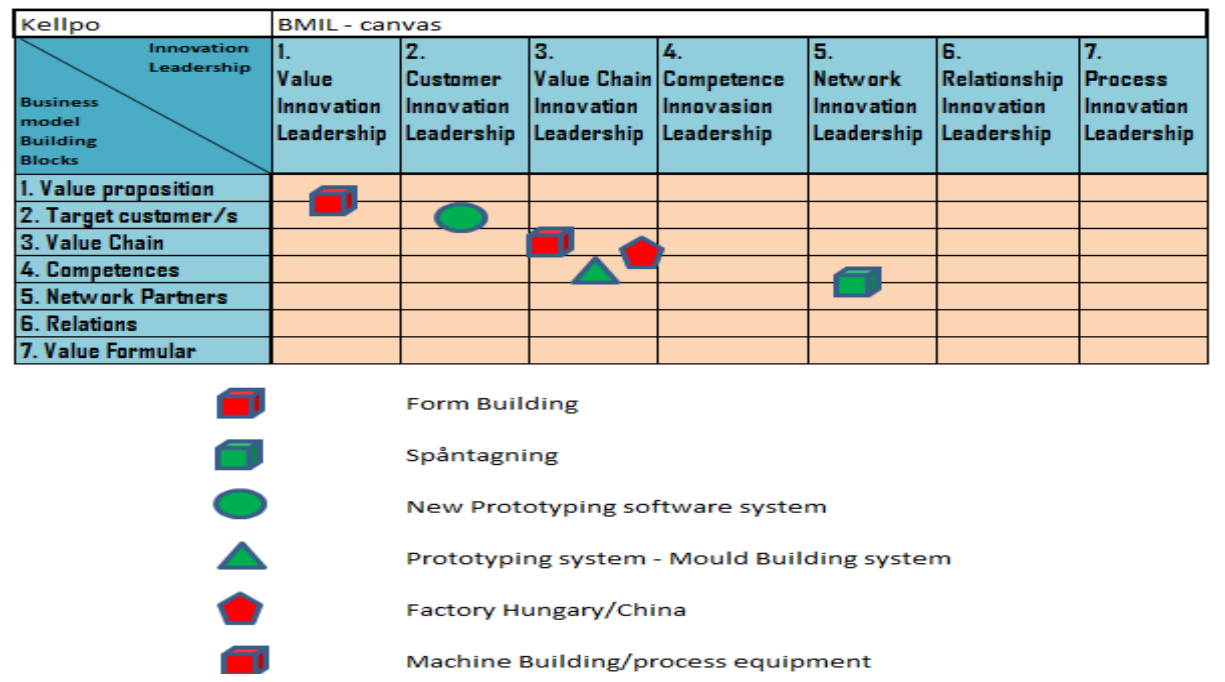

Figure 6. Kellpo case - BMs related to BMIL task 
We verified that each of Kellpo's BM's called for different innovation leadership lines/viewpoint perspective to make them move into a direction of interest of Kellpo. In the model we placed the BM's where they are placed at the moment in the BMIL strategy canvas.

We found that each Innovation leadership line could influent the innovation process in very different ways individually but also together. In the table beneath each of the 7 lines of innovation leadership are presented related to strength, weaknesses, opportunities and threats.

Table 2. Innovation leadership related to view of BMI

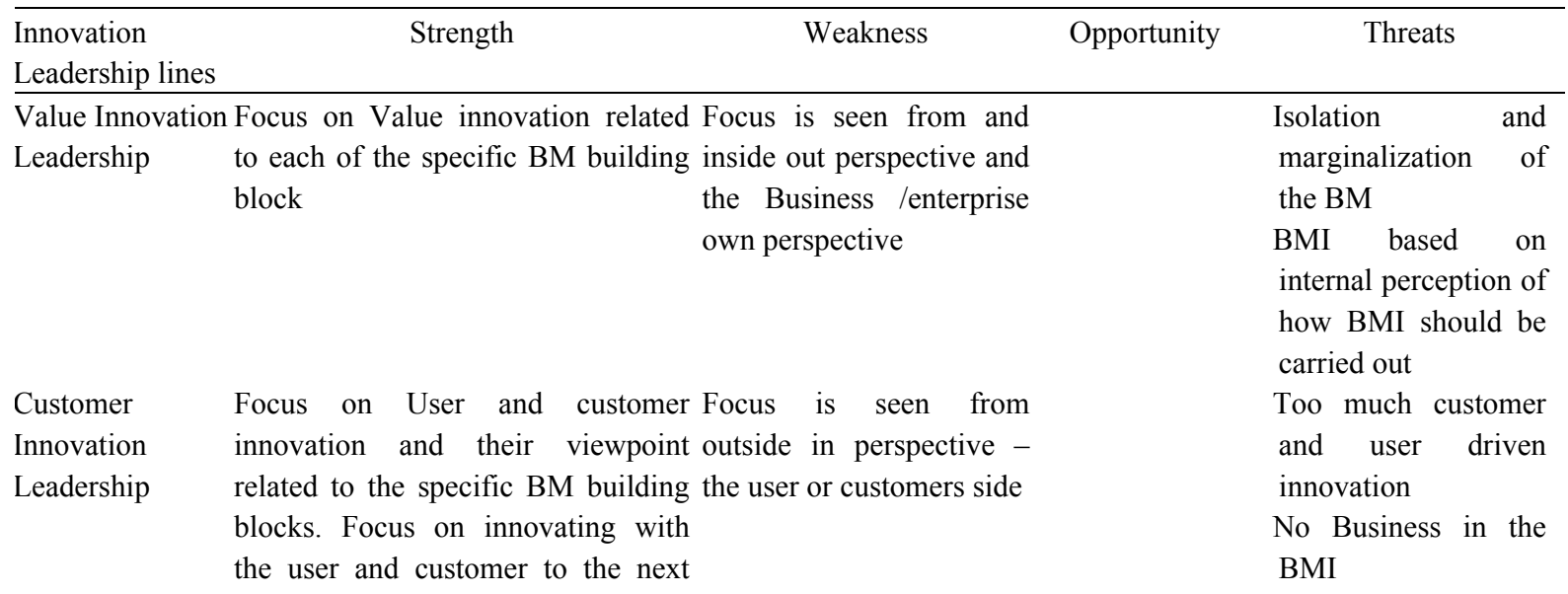
step on the users or customers innovation process in their $\mathrm{BM}(\mathrm{s})$

Value Chain Focused on value chain innovation Focus is seen from inside Unpacking of Innovation and the value chains view point in perspective - the value Value Chain Leadership related to each BM block. chain Internal perspective [Internal] demands

Competence Focused on competence innovating - Focus is seen from inside Unpacking of Innovation technology-, HR-, organisational in perspective - the competence Leadership system and culture innovation competence internal demands related to each BM building block perspective

Network Focused on network innovating Focus is seen from Unpacking of Innovation related to each BM building block outside in perspective - network partner the network side BMI demands

Too Much focus on Value Chain BMI demands

Too competence BMI demands

Too much Network BMI demands

Leadership

Relationship

Focus on relation and relationship Focus is seen from Unpacking of Innovation innovating to each $\mathrm{BM}$ building outside in and inside out Relations

Leadership block perspective - very demands complex

Process innovation Focus on process innovation - Focus is seen from Increasing the looking innovation related to horizontal outside in BMI field Leadership different processes and in different perspective - the process time perspectives both before, under perspective side and after the specific BM.

\subsection{Innovation Leadership Related to Different Point of Time in BMI Life Cycle}

The use case research showed that the 7 building blocks in a BM could be related to all Innovation Leadership lines so that each Innovation Leadership line could really work with each of the 7 building block at a certain point in the innovation process - "the point of time in the BM lifecycle". This not to say that this was optimal done always by the businesses. There are strengths, weaknesses, opportunities and threats related to all innovation leadership lines and their effect are very much dependent on the BMI task and BMI context. Those responsible for BMIL strategy formulation must be aware of this and learn about this through learning and practice. 
Katalabs was e.g. initially not focusing much on customer and customer innovation leadership but instead on getting users to their BM. We found that this was changed by Katalabs, as Katalabs began to run out of sweat money. Katalabs was "stucked" in their BMI strategy. Katalabs had to focus much more on getting users to become customers and especially have users to help develop the Katalab platform to attract other customers.

Some of Katalabs BMs had only users and no customers, which initially was not an issue to Katalabs because they believed that the users would eventually lead them to the customers - and then venture capital (Like Facebook case - and Face book BMIL strategy). This BMIL strategy was changed over time as Katalabs began to run out of free resources - and "sweat money". They kept themselves as a running business by earning money on other BM's (Cancer BM, Bornhom BM e.g.) in their BM portfolio and also by giving those working on the new BM (Kataspace BM) "futures". However they were eventually forced to change BMIL strategy and had to change BMIL focus by focusing more on customer innovation leadership and network innovation leadership. (Lindgren 2012)

\subsubsection{Orchestrating Innovation Leadership Lines Related to BMIL}

The Aikon case showed us quit another but very interesting thing related to BMIL practice. Aikon managers were, unlike some of the other use cases, focused much more on using two innovation leadership lines at the same time - Customer Innovation Leadership and Network Innovation Leadership, in the BMIL canvas simultaneously. They target particularly the customer building block in each of their individual BMs but in two different innovation leadership lines. This was amongst others due to the fact that Aikon had already the capacity and competence on value proposition innovation - especially products innovation - and value chain innovation leadership but they were in deep lack of critical mass of customers.

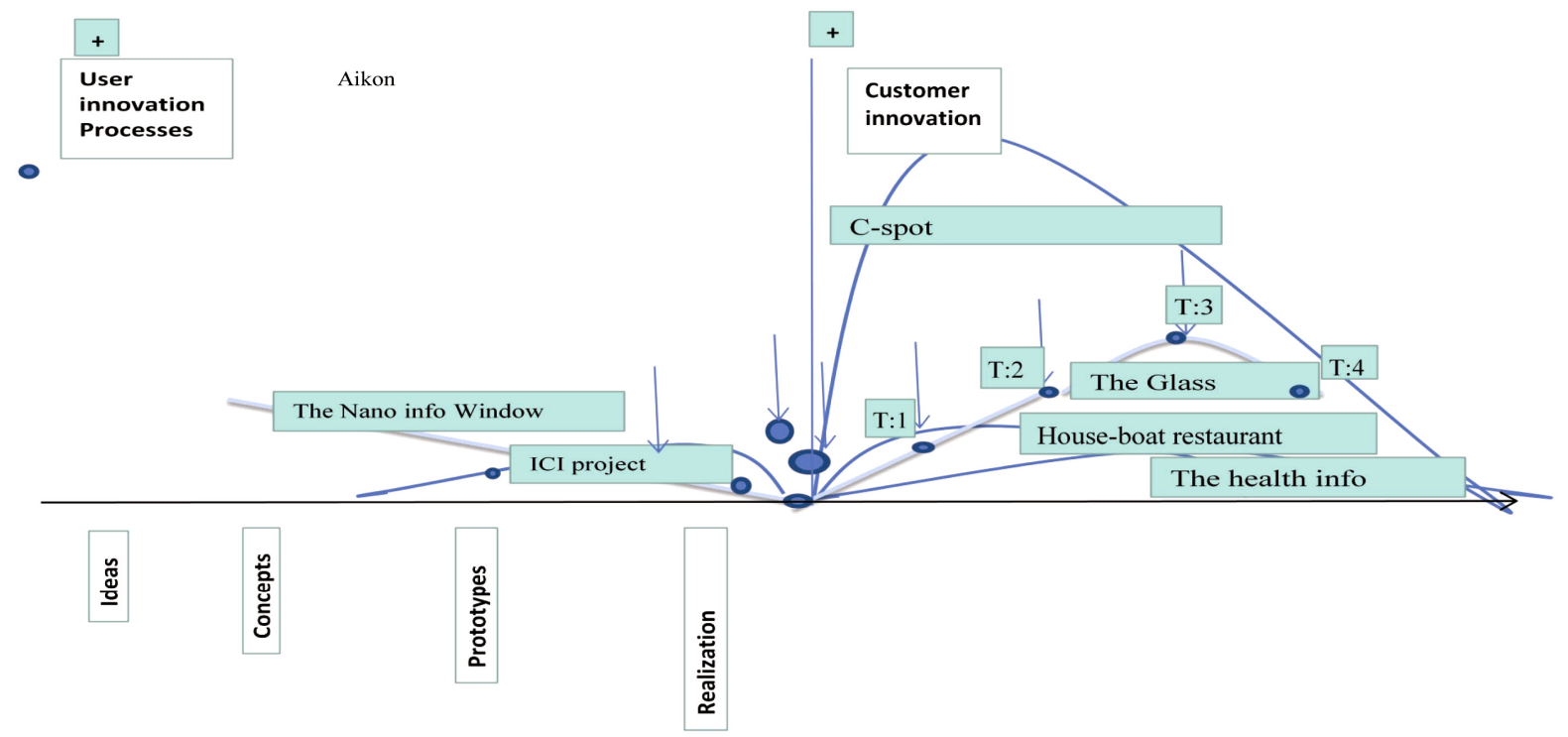

Figure 7. Aikon case - orchestrating innovation leadership to the BMI task related to time of BMI

Via orchestrating of two innovation leadership lines - the customer innovation leadership with the network innovation leadership line - and combining focus on customers with a focus on network partners building block in two of their other BMs, Aikon gained access to more and better customers to their BM hereby.

Further they choose to eliminate two BMs because they were not generating profit. Aikon wanted to achieve focus in their overall business innovation - their portfolio of BM's. Therefore the glass kitchen and the health info system were faced out of their BM portfolio. A very radical BMIL excluding strategy was registered as Aikon choose taking a whole BM out of the BM portfolio. A more incremental BMIL strategy would have been just to change some of the building blocks in the BMs but Aikon managers could not see which building block and how to change these.

The challenge to the AIKON enterprise but also to other use cases studies was always to carefully analyze the $\mathrm{BM}$ innovation task related to each BM and then choose between multitude and variable lines of innovation leadership. To do this Aikon was in lack of a BMIL service tool that could show them different scenarios and analysis of the BMIL task. This could be developed with different BMIL strategy scenarios visualized in a BMIL 
service tool.

\subsubsection{A network- Relationship and Process Oriented BMIL Task}

The Infolink Case solved the BMI challenges in ways different than for the use cases that we described so far, namely primarily via orchestrating Network-, Relationship-, and Process innovation leadership. Infolink used their network and relations to get new customers, new suppliers and new knowledge partners. They focused specifically on relationship innovation leadership to continuously increase their BM platform. We tried to illustrate this in the figure beneath.

\begin{tabular}{|c|c|c|c|c|c|c|c|}
\hline Info Link & BMIL - car & ivas & & & & & \\
\hline $\begin{array}{l}\text { Leadership } \\
\text { Business } \\
\text { model } \\
\text { Building } \\
\text { Blocks }\end{array}$ & $\begin{array}{l}1 . \\
\text { Value } \\
\text { Innovation } \\
\text { Leadership }\end{array}$ & \begin{tabular}{|l}
. \\
Customer \\
Innovation \\
Leadership
\end{tabular} & $\begin{array}{l}3 . \\
\text { Value Chain } \\
\text { Innovation } \\
\text { Leadership }\end{array}$ & $\begin{array}{l}4 . \\
\text { Competenc } \\
\text { e } \\
\text { Innovasion } \\
\text { Leadership }\end{array}$ & \begin{tabular}{|l}
5. \\
Network \\
Innovation \\
Leadership
\end{tabular} & \begin{tabular}{|l|}
6. \\
Relationship \\
Innovation \\
Leadership
\end{tabular} & \begin{tabular}{|l|}
7. \\
Process \\
Innovation \\
Leadership
\end{tabular} \\
\hline 1. Value proposition & & & & & & & \\
\hline 2. Target customer/s & & & & & & & \\
\hline 3. Value Chain & & & & & & & \\
\hline 4. Competences & & & & & & & \\
\hline 5. Network Partners & & & & & & & \\
\hline 6. Relations & & & & & B & & \\
\hline 7. Prafit Formular & & & & & & & \\
\hline
\end{tabular}

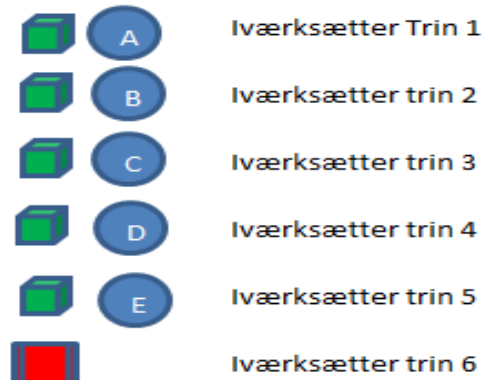

Figure 8. Infolink case - BMIL canvas

The green marked area shows where Infolink puts their main BMIL strategy effort. Infolink is very special, when compared with many of the other enterprises, because Infolink, in most cases, does not pay network partners for supplying their Infolinks business and business models. The network partners make their business indirectly and as a synergy effect out of the present users at Infolinks courses.

Hereby we discovered some relations in BMI that are not the same as those inside the BM - building block 6 in our original business model framework. These relations go beyond the relations inside a BM and these are now under research in our research group.

\subsection{BMIL - A Vertical and Horizontal Dimension of BMIL}

In some of the use cases we studied we found that businesses were trying to look out of their existing BM and even business. They consider both vertical and horizontal process dimension to their BM. We illustrate this by two examples.

\subsubsection{A Vertical Dimension of BMIL Strategy}

In the Provital case the business commenced to develop a BM for the water cleaning sector. However they soon were contacted by other businesses and potential customers operating in other industries - smoke cleaning, car wash line of business and others about using their BM in other line of businesses. This we tried to illustrate in the figure beneath as a vertical dimension of BMIL strategy. 


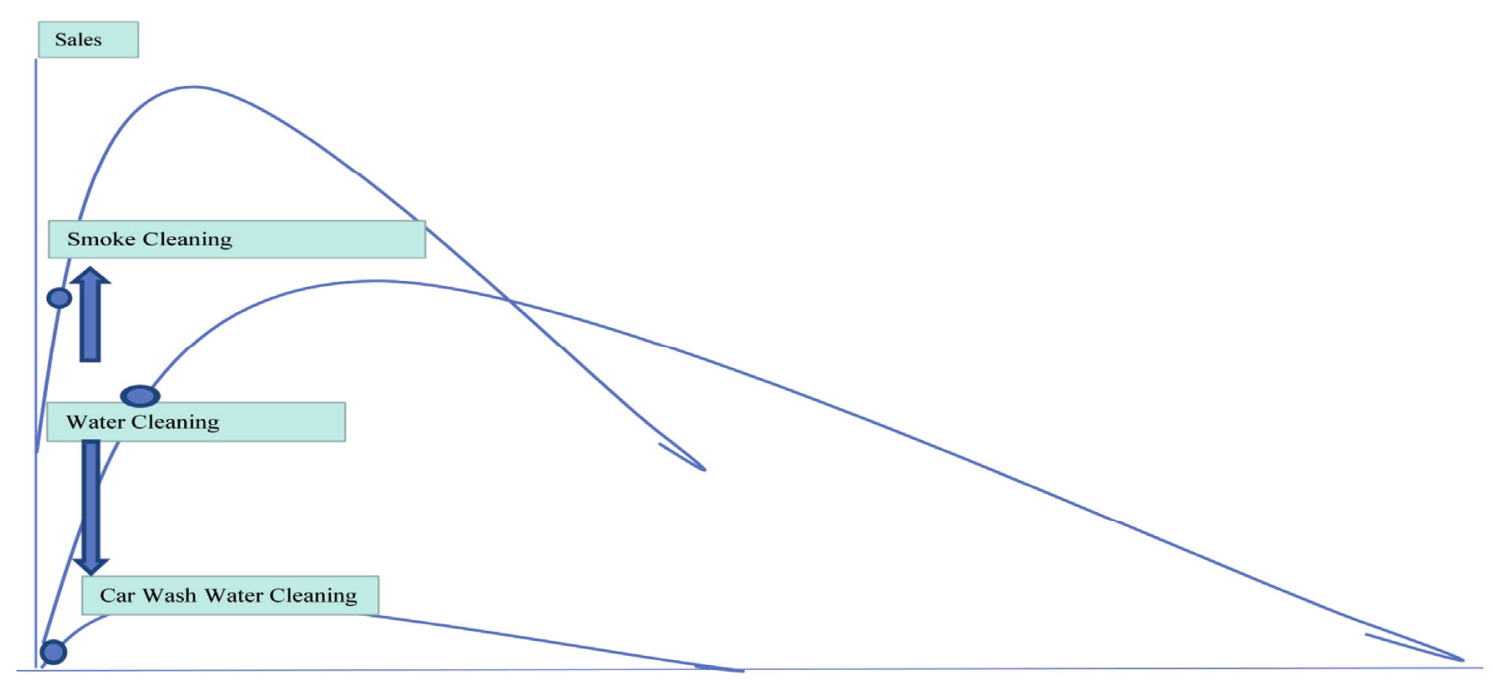

Figure 9. Provital case - vertical BMIL

Provital considered to move into two other industries with their BM - or adjusted existing BM - to these industries. In 2012 Provital moved into the smoke cleaning industry with their BM with success and they tried also to move into the Car wash water industry - however at the moment with no success. The BM was in the last case not developed enough to be accepted in this market.

\subsubsection{A Horizontal Dimension of BMIL}

In the Infolink case company consider BMI via looking forwards- and backwards the existing BMI process. We named this the Horizontal dimension of BMIL - because Infolink looks for new BM's opportunities along the existing BMI process - or more specific in the lifecycle of the BM and considers what happens before, during and after the BM consumption process. By doing this Infolink's "eyes" were suddenly opened up to new BMI potentials, which may - may not be taken into consideration and later integrated in the Infolink BM portfolios. In Infolink case Infolink found that entrepreneurs after $5^{\text {th }}$ phase courses wanted to learn more. However Infolink did not have a BM for this marked. Infolink began BMI idea generation on this and found that they had to develop a "TO BE" BM that was very different to their "AS IS" and existing BM. The potential new BM was however out of scope with their existing Business BM portfolio. Inforlink is still considering whether this BM should be adopted in their BM portefolio.

This BMI process opened Infolinks mind to new BMI possibilities - new customer groups, new value chain systems e.t.c. but on a horizontal BMIL level.

\section{Discussion}

The challenge to SMEs formulating BMIL strategies seems in a globalized world to be even harder, more complex and more risky.

Our case research showed that many businesses was placed outside the core of BMI and therefore suffered and often played a secondary and not very attractive role in the BMI process (Katalabs, Kellpo, Aikon and Provital case). Some enterprise we studied were even marginalized by BMI and their value proposition or even BMs were "cruelly" copied by customers, suppliers or competitors, when they had gained and "drained " the most important values and competences (sometimes core competences) of the business enterprise (Kellpo, The Machine builders).

At least the enterprises mentioned above knew about this and could begin to do something about it by formulating or changing their BMIL strategy (Lindgren 2012). Worse is however if the companies cannot see that they are left out of or beginning to be left out of - the core of BMI. Then they miss opportunities or are slowly dragging their business out of business (Kotler 1984).

The above mentioned context and position of our study on SME's BMI context is not special to SMEs as such. The position big companies as e.g. Facebook, Google and Apple have today of course, gives them some competitive advantage because they, today, are placed inside the core of the BMI process. However, even they have to struggle with their BMIL to keep them inside the core of the innovation process. Even these mastodons 
are in risk of having their BM's copied. They also have to think carefully about BMIL. A look into how Apple, Google, Facebook, Microsoft and Amazone struggle to keep them self as strategic BMI leaders and thereby in the core of BMI. (Lindgren 2012) shows very well that BMIL is not just a matter for SME's

BMIL - showed indeed in our research to be a challenge and sometimes a very complex thing to handle for leaders responsible for BMI. Especially startup businesses - types as Katalabs and Aikon - were often hung up in daily survival activities and lack of information together with lack of analytical tools preventing them to think about strategic BMI. This gave the businesses big challenges and waste of resources to bring themselves back into the core of the BM innovation process.

These businesses were in lack of time and resources to perform BMIL. They tried however to seek different ways to achieve a better position for their existing "TO BE" and "AS IS" BM's positions related to the core of the BMI processes. These BMIL strategy choices were however not always coordinated and did not always bring them into a better strategic position - long time business advantage. The challenge - or paradox - as startup business is often that you need to survive and are often living from day to day simultaneously with the necessity at the same time that you need to do BMIL. Often the enterprises knew they had to do BMIL to survive but they were really not capable to do this because of the above mentioned.

Some case enterprises we studied jump to solve their general Business situation via bringing new BMs into the BM portfolio. This often turned out not to solve the BMI task of the business, drained resources from the business and disturbed the overall focus of BMIL strategy in the business.

To set up the right "mixture" of different Business Model innovation leadership lines in a BMIL strategy that fits different BM's needs BMIL carried out with excellence. From our case studies we could register that different innovation leadership lines combination could empower but also diminish the BMIL strategy success and effect. Therefore it is necessary to find, learn and practice how to "construct" the right mixture of innovation leadership lines and also find which focus on the building blocks in the specific BM to innovate. SME managers responsible for BMIL strategy have to make and have to have the possibility to do more scenarios of BMIL strategy before choosing final BMIL strategy. There are always more strategic roads to follow - and no one fits all BMI contexts. To do these BMIL scenarios SME's seems to need better BMIL service tools and quicker BMIL analytical tools that can give them BMI overview related to possible BMIL strategies, possible BMI strategy consequences, possible BMIL strategy results and control of chosen BMIL strategy performance.

On behalf of these observations in the use cases we have commenced the development of proposals for BMIL strategy service tool by developing a questionnaire and toolbox for BMIL strategy formulation. We have supported this with some supporting BMIL analyzing tools, which we expect have to be updated and increased with other tools in the future. The tools are related to where we initially believe they are best suited to help the managers of BMIL. All of this is going to be presented in autumn 2012.

\section{Conclusion}

The generic BMIL strategies drawn from our research on the SME cases show a first picture of what SME's strategically do and how they practice Business model innovation leadership. Via a careful analysis of SME's different BMIL approaches - their strategic BMI tasks, contexts and their BMIL vision, mission, goals and strategies we analysed each of their BM's. The strategic BMI task analyse shows

- $\quad$ BMI is carried out in businesses in many different ways related to the various BMI tasks. However very few of the enterprises we investigated do BMIL and very few have really a BMIL strategy.

- What the SME's are targeting and not targeting related to existing BM(s) and new BM(s) today (AS IS). It also shows quiet clearly what SME's do and what they can/will/could do/target through strategic BMI (To $\mathrm{Be}$ ). BM and Innovation Leadership literature SME have until now mainly considered BMI as development of the value proposition in the BM and on single BM perspective (from Idea to market implementation) of BMIL. SME's are generally doing the same according to our research and their BMIL strategy and practice is mainly build around a single business and BM strategy approach.

In our proposed BMIL framework this is define as value innovation leadership approach and strategy. Value innovation leadership is focused on the business viewpoint - an inside out viewpoint - related to the 7 building blocks of the BM. Our research also shows that the BMI is primarily built upon and focused on managing product-, service and process innovation processes - the upper corner part of value innovation leadership- . This is in the BMIL framework just a very small part of the real BMIL potential and indicates that Businesses are not really using the full potential of BMI and BMIL strategies.

Today it is the task for managers at the BMIL level to manage and do the process of strategically BMIL thinking, 
decision and formulating the future BMIL strategy. They also at the same time have to secure implementation of the BMIL strategy. It was documented that different BMI strategies are often interrelated with each other and there is also often a very strong relationship between different building blocks and even BM's in a Business BM portfolio. Different BM is related to other BM and this is often built in to SME's BMIL strategy during the BMIL process.

On behalf and based on our European and US business cases a first conceptual frame work model of BMIL and BMIL strategy was developed; where 7 lines of Innovation Leadership (BMI viewpoints) were identified and then related to the 7 building blocks in the BM. The framework tries to extend, build upon and go beyond previous existing BMI strategy views, issues and tools.

BMIL focuses on the strategic part of BMI - Question Why, What and how should a business do strategic BMI. BMIL seeks to optimize the business investment in BMI focusing on both short- and long-term success criteria of the business - with the aim of moving the business strategically in to "the core of the BMI process" and hereby get business advantage as a result of BMI.

BMIL focus on strategically innovating the BM both from the external side of the business enterprise - Value innovation leadership, Customer innovation leadership and Network innovation leadership - and Internal side of the enterprise -Value chain innovation leadership, Competence innovation leadership. BMIL leadership cover the whole BMI process - "the tree of innovation" (Taran et al. 2009) - considering all building blocks in the business model as objects for innovation related to the 7 lines of innovation leadership. BMIL consider both the leadership and the strategy part of BMI in this context.

BMIL further consider in a time perspective the entire BMI process before, under and after each BMI has(ve) taken place - process innovation leadership. BMI leadership (BMIL) focuses on Relation innovation leadership related to each individual BM building block in the enterprise. Finally which was not covered deeply in this paper BMIL also focus on innovation leadership across different BM both those who are on their way to the market or are already living their life on the market - the horizontal dimension of BMIL.

The framework model propose managers responsible for BMI to carry out BMIL via including 3 main focus areas

1) Generate and recognize new BM idea and BM concepts - continuous BM innovation at the "frontend" of the BMI innovation process.

2) Leading strategically BMI via orchestrating different strategic lines of innovation leadership, combining and catching these BMIL lines synergy effects and focusing on isolating the significantly most valuable new BMI ideas and bring them right to the market and beyond.

3) Bring BMIL up to a point of leading a multitude of BM - via the multi business model platform - both before, under and after the BMI process has taken place - continuous BMIL.

\section{Further Research}

New methods and more research to better encompass SME's BMI and BMIL strategies is highly needed. Especially we believe that more digitalization of SME's BM's and BMIL strategy process will give better knowledge about these issues. The digitalization of the BM will also give possibilities for BMI leaders to apply and see BMI scenarios and effects of their BMIL strategies.

\section{References}

Afuah, A., \& Tucci, C. (2003). Internet Business Models and Strategies. Boston: McGraw Hill Irwin.

Boer, H., \& During, W. E. (2001). Innovation - What innovation? A comparison between product, process and organisational innovation. International Journal of Technology Management, 22(1-3), 83-107. http://dx.doi.org/10.1504/IJTM.2001.002956

Bryman, A. (2004). Qualitative research on Leadership: A critical but appreciative review. The Leadership Quarterly Elsevier INC.

Chesborough, H. (2007). Open business models: How to thrive in the new innovation landscape. Boston: Harvard Business School.

Hammel G. (2007). Retrieved from http://www.youtube.com/watch?v=KCWHFqNKH40

Lindgren P. (2011). NEW Global ICT-based Business Models. The River Publishers Series in Standardisation. 
Lindgren, P., Rasmus J., Kristin F. S., \& Yariv T. (2011). Towards a sixth generation of business model innovation models. 12th International CINet Conference Århus - Doing More with Less Publication.

Lindgren, P., Taran, Yariv., \& Boer, H. (2010). From single firm to network based business model innovation. International Journal of Entrepreneurship and Innovation Management, 12(2), 122-137. http://dx.doi.org/10.1504/IJEIM.2010.034417

Lindgren, P., \& Yariv T. (2011). A Futuristic Outlook on Business Models and Business Model Innovation in a Future Green Society. Journal of Green Engeenering Journal of Green Engineering, 1-10.

Lindgren, P., Yariv T., \& Kristin F. S. (2011). Business model innovation leadership - How to strategically lead Business Model innovation? Journal of Strategic Communication and Computer (JCC). Chicago: David Publishing Company.

Magretta, J. (2002). Why business models matter? Harvard Business Review, 80(5), 86-92.

Morris, M., Schmindehutte, M., \& J. Allen. (2003). The entrepreneur's business model: toward a unified perspective. Journal of Business Research, 58(6), 726-735. http://dx.doi.org/10.1016/j.jbusres.2003.11.001

Osterwalder, A., Pigneur, Y., \& Tucci, L. C. (2004). Clarifying business models: Origins, present, and future of the concept. Communications of AIS, No. 16, pp. 1-25.

Scharmers, C. Otto. (2009). Therory U: Leading from the Future as It Emerges. San Francisco: Berret - Koehler publisher.

Schumpeter, J. A. (1957). Capitalism, Socialism and Democracy. Harper Perennial.

Taran. (2011). Re-thinking it All: Overcoming Obstacles to Business Model Innovation Center for Industrial Production. Ph.D Thesis, Aalborg University.

Teece, D. J. (2010). BusinessModels, Business Strategy and Innovation. Long Range Planning, 43(2-3). http://dx.doi.org/10.1016/j.lrp.2009.07.003

Tidd, J., Bessant, J. B., \& Pavitt, K. P. (2005). Managing Innovation. Integrating Technological, Market and Organizational Change. Chicester: John Wiley \& Sons.

Ulrich, K. T., \& Eppinger, S. D. (2000). Product Design and Development (2nd ed.). Irwin McGraw-Hill.

Zott C., Amit R., \& Massa L. (2011). The Business Model: Recent Development and Future Research. Journal of Management. http://dx.doi.org/10.1177/0149206311406265

Zott, C., \& Amit, R. (2008). The fit between product market strategy and business model: Implications for firm performance. Strategic Management Journal, 29, 1-26. http://dx.doi.org/10.1002/smj.642

Zott, C., \& Amit, R. (2009). The business model as the engine of network-based strategies. In P. R. Kleindorfer \& Y. J. Wind (Eds.), The network challenge (pp. 259-275). Upper Saddle River, NJ: Wharton School Publishing.

Zott, C., \& Amit, R. (2010). Designing your future business model: An activity system perspective. Long Range Planning, 43, 216-226. http://dx.doi.org/10.1016/j.lrp.2009.07.004

Zott, C., Amit, R., \& Massa, L. (2011). The business model: recent developments and future research. Retreived from http://ssrn.com/abstract=1674384

Appendix 1. Innovation Leadership lines

\begin{tabular}{ll}
\hline Innovation Leadership view points & Definition \\
\hline Value Proposition Viewpoint & Value Proposition in focus \\
User and Customer Viewpoint & User and customer in focus \\
Value Chain Viewpoint - Internal & Value Chain in focus \\
Competence Viewpoint & Competence in focus \\
Network Viewpoint & Network and network partner in focus \\
Relation Viewpoint & Relation in focus \\
Process Viewpoint & Process of BM in focus \\
\hline
\end{tabular}

